14,12

\title{
Поиск оптимальных условий монолитизации реакторного порошка сверхвысокомолекулярного полиэтилена
}

\author{
(С) Л.П. Мясникова ${ }^{1}$, В.Ф. Дроботькоㄹ, А.П. Борзенко ${ }^{2}$ Ю.М. Бойко \\ B.A. Марихин ${ }^{1}$, С.А. Терехов ${ }^{2}$, М.А. Яговкина ${ }^{1}$ \\ ${ }^{1}$ Физико-технический институт им. А.Ф. Иофрфе РАН, \\ Санкт-Петербург, Россия \\ ${ }^{2}$ Донецкий фризико-технический институт им. А.А. Галкина, \\ Донецк, Украина \\ E-mail: liu2000@mail.ru
}

Поступила в Редакцию 20 июля 2021 г.

В окончательной редакции 20 июля 2021 г.

Принята к публикации 22 июля 2021 г.

С целью выяснения возможности спекания реакторных порошков сверхвысокомолекулярного полиэтилена под давлением при температуре выше его равновесной температуры плавления $\left(T_{m}^{0}\right)$ при атмосферном давлении без катастрофического изменения внутренней структуры частиц, проведен сравнительный рентгеноструктурный анализ в больших углах образцов, спеченных при температурах ниже $\left(T<T_{m}^{0}\right)$ и выше $\left(T>T_{m}^{0}\right)$ этой температуры и охлажденных в разных условиях. Проведен структурный анализ кривых рассеяния, записанных на порошковом дифрактометре D2Phaser Bruker от спеченных и охлажденных в разных условиях реакторных порошков СВМПЭ и рассчитаны размеры кристаллитов. Найдено, что повышение температуры спекания выше $T_{m}^{0}$ не вносит существенных изменений в кристаллическую структуру полимера, и изготовленные прекурсоры могут быть использованы для дальнейшего ориентационного упрочнения.

Ключевые слова: реакторные порошки сверхвысокомолекулярного полиэтилена, монолитизация, спекание, рентгеноструктурный анализ в больших углах.

DOI: 10.21883/FTT.2021.11.51601.164

\section{1. Введение}

В настоящее время активно разрабатывается безрастворный (сухой) метод получения высокопрочных, высокомодульных нитей и пленочных лент сверхвысокомолекулярного полиэтилена (СВМПЭ) непосредственно из продуктов синтеза, так называемых реакторных порошков. Этот метод является альтернативным дорогому и экологически небезопасному методу гель-технологии и заключается в спекании порошка при температуре ниже температуры плавления полимера с последующей ориентационной вытяжкой.

Фирма Tejin-Aramid (The Netherlands) освоила производство высокопрочных и высокомодульных лент СВМПЭ сухим методом и, начиная с 2012 года, выпускает ленты СВМПЭ под торговой маркой Endumax. По прочности $(2.5 \mathrm{GPa})$ эти ленты все же уступают прочности волокон Dyneema (3.6ГПа), производимым по гель-технологии фирмой DSM (The Netherlands). В то же время в лабораторных условиях, как в России [1-3], так и за рубежом [4] получены ориентированные нити СВМПЭ с гораздо более высокими механическими характеристиками. Так, например, в группе проф. S. Rastogi (The Netherlands) получены пленочные нити СВМПЭ из порошка, синтезированного на одноцентровом постметаллоценовом катализаторе F1 с пределом прочности на разрыв $4 \mathrm{GPa}$ и модулем упругости $200 \mathrm{GPa}$ [4]. Из реакторных порошков СВМПЭ, синтезированных в лаборатории проф. С.С. Иванчева (ИВС РАН, Россия) на одноцентровом пост-металлоценовом катализаторе F-97 в ФТИ им. А.Ф. Иоффе в лаборатории физики прочности также получены высокопрочные пленочные нити СВМПЭ с пределом прочности на разрыв до 4.5 GPa и модулем упругости $180 \mathrm{GPa}$ [5].

Несмотря на достигнутые успехи в получении высокопрочных пленочных нитей, все же их характеристики еще далеки до теоретических оценок. При модуле упругости $200 \mathrm{GPa}$ теоретический предел прочности нитей СВМПЭ должен составлять около $20 \mathrm{GPa}$. Поэтому поиск путей улучшения прочностных характеристик ориентированных нитей СВМПЭ продолжается.

Достижение высоких прочностных характеристик зависит от двух моментов: структуры частиц реакторного порошка, оптимальной для ориентационного вытягивания, и возможности создания прочных когезионных связей между частицами, препятствующих преждевременному разрыву образца в процессе вытяжки до достижения предельно возможной степени удлинения.

Оптимальной структурой насцентного порошка считается структура с минимальным количеством молекулярных зацеплений, число которых зависит от температуры полимеризации, типа катализатора и многих других условий синтеза. Прочность межчастичных границ определяется условиями спекания порошка. При этом важным является сохранение минимального количества зацеплений, существовавших в исходной структуре. 
Целью настоящей работы являлось сравнительное исследование кристаллической структуры реакторного порошка СВМПЭ после спекания под давлением выше и ниже равновесной температуры плавления полимера с помощью рентгеноструктурного анализа в больших углах.

\section{2. Экспериментальная часть}

\section{1. Материалы}

Исследования проводились на реакторном порошке (РП) СВМПЭ-5224, синтезированном в лабораторных условиях в Институте высокомолекулярных соединений РАН, (Санкт-Петербург) путем суспензионной полимеризации в толуоле по методике, описанной в [6], с использованием титан-галоидных феноксииминных катализаторов особого строения PS-1229, активированных метилалюмоксаном. Молекулярная масса реакторного порошка 5224 составляла $M w=3.1 \cdot 10^{6} \mathrm{~g} / \mathrm{mol}$, $T_{\text {полим }}=40^{\circ} \mathrm{C}$, насыпная плотность $\rho_{\text {насып }}=0.051 \mathrm{~g} / \mathrm{cm}^{3}$, фракция $250<d<850 \mu \mathrm{m}$. Такой порошок для исследований был выбран на основании литературных данных, свидетельствующих о формировании оптимальной структуры РП СВМПЭ для твердофазной переработки при синтезе СВМПЭ на постметаллоценовых катализаTopax [6].

\section{2. Приготовление образцов}

Образцы для исследования готовили по принципу порошковой металлургии, давно применяемой в промышленности при переработке тугоплавких металлов, керамики и нерастворимых и неплавких полимеров, типа политетрафторэтилена, полибензимидазола и др. Схема приготовления исходных образцов (прекурсоров) для последующего ориентационного упрочнения из РП СВМПЭ включает два этапа:

1. Компактирование (уплотнение) РП при комнатной температуре для создания наиболее тесного контакта между поверхностями ближайших соседних частиц РП СВМПЭ и увеличения адгезионной прочности компакта за счет максимально возможного уменьшения свободного объема и изгнания „пойманного“ воздуха.

2. Спекание полученного компакта с целью создания наибольшего количества когезионных связей между исходными частицами РП, обеспечивающих механическую прочность прекурсора, позволяющую в дальнейшем осуществлять деформационное упрочнение прекурсора путем высокотемпературной многостадийной ориентационной вытяжки без преждевременного разрыва ориентируемого образца до достижения им предельных ориентационных удлинений. Спекание обычно осуществляется при одновременном воздействии давления и температуры, не превышающей $T_{m}$ исходного РП.

При этом выдвигаются принципиально важные требования к выбору значений сжимающих усилий на стадии компактирования и повышенных значений температуры и сжимающих усилий на стадии спекания, при которых в процессе приготовления прекурсора необходимо в максимальной степени сохранить специфическую надмолекулярную организацию, сформировавшуюся в процессе синтеза исходных РП.

Первый этап - компактирование РП, осуществлялся методом холодного прессования (при комнатной температуре) при использовании специально изготовленной закрытой цилиндрической пресс-формы с внутренним диаметром $20 \mathrm{~mm}$ и с двумя тщательно подогнанными по диаметру пуансонами. Торцевые поверхности плоскопараллельных пуансонов полировались до шероховатости менее $1 \mu \mathrm{m}$.

Для компактирования между пуансонами помещали навеску порошка СВМПЭ весом $60 \mathrm{mg}$ и устанавливали пресс-форму в гидравлический пресс. Выбор величины сжимающего давления и длительности нахождения компакта под нагрузкой осуществлялся с учетом результатов работ [7,8]. В работе [7] были получены данные о сжимаемости коммерческих порошков СВМПЭ с молекулярной массой $M w>2 \cdot 10^{6} \mathrm{~g} / \mathrm{mol}$, с различной насыпной плотностью и различными размерами и формами частиц. Кривые сжимаемости таких порошков представляют собой зависимости относительного уплотнения, (так называемого параметра уплотнения DR) от величины сжимающего давления в пресс-форме. Для каждого не спеченного (сырого) порошка DR увеличивается с давлением, сначала быстро, а затем скорость уменьшается и кривые выходят на плато. Каждый порошок имеет свой характерный уровень плотности на плато, который меньше полной плотности материала. Оказалось, что для всех исследованных порошков выход на плато происходил при одном и том же значении внешнего сжимающего давления около $100 \mathrm{MPa}\left(10 \mathrm{Kg} / \mathrm{mm}^{2}\right)$, т. е. при сравнительно небольших давлениях. Этот результат был также подтвержден в работе [8], где авторы исследовали реакторные порошки СВМПЭ с одинаковой плотностью $0.961 \mathrm{~g} / \mathrm{cm}^{3}$, молекулярными массами $M w=1.74 \cdot 10^{6}$ и $1.6 \cdot 10^{6} \mathrm{~g} / \mathrm{mol}$ и различной насыпной плотностью 0.057 и $0.206 \mathrm{~g} / \mathrm{cm}^{3}$. Кривые сжимаемости таблеток также выходили на линейный участок при давлении около $100 \mathrm{MPa}$. Очевидно, что из-за наблюдаемого явления плато нет преимущества в использовании давлений, превышающих 100-200 МРа. Для получения более высоких плотностей необходимо изменять характеристики порошка, а не давление.

С учетом полученных в $[7,8]$ результатов мы проводили компактирование РП в вышеописанной пресс-форме при комнатной температуре под давлением $P=100 \mathrm{MPa}$ в течении $15 \mathrm{~min}$. Затем давление на прессе сбрасывалось при открытии соответствующего клапана. При этом обращали внимание на то, чтобы скорости набора и сброса давления были примерно одинаковыми для всех таблеток. В результате получали исходные компактированные таблетки диаметром $D=20 \mathrm{~mm}$ и толщиной $h_{1}=0.20 \mathrm{~mm}$, которая несколько увеличивалась до 
$h_{2}=0.215 \mathrm{~mm}$ после выдерживания в эксикаторе с влагопоглощающей крошкой при комнатной температуре и атмосферном давлении в течение суток.

Второй этап - спекание компактированных РП проводили под давлением $100 \mathrm{MPa} \mathrm{в} \mathrm{различных} \mathrm{условиях.}$

Прежде чем описать конкретные условия приготовления спеченных образцов для рентгеноструктурного анализа, обратимся еще раз к механизму создания монолитной пленки из РП. Как уже упоминалось выше, спекание компактированного порошка проводится для создания прочного сцепления между частицами РП и получения механически прочного прекурсора для ориентационного упрочнения. „Залечивание“ межчастичных границ достигается за счет образования проходных сегментов молекул между частицами в процессе диффузионного проникновения свободных концевых отрезков макромолекул из соседних контактирующих частиц друг в друга. С одной стороны, для увеличения молекулярной подвижности и ускорения диффузии желательно существенно повысить температуру спекания, однако, при этом может произойти нежелательная перестройка исходной надмолекулярной структуры РП или даже переплавление полимера, если проводить спекание при температуре выше температуры плавления полимера $T \geq T_{m}^{0}$. Поэтому спекание всегда производится при температуре ниже $T_{m}^{0}[9]$.

Однако в ряде экспериментальных работ было обнаружено увеличение температуры плавления полимеров с ростом гидростатического давления. Так в работах [10] и [11] при исследовании кинетики кристаллизации натурального каучука, используя дилатометрические методы для расширенного диапазона температур и гидростатических давлений до $1100 \mathrm{~atm}$ и $2000 \mathrm{~atm}$, было определено влияние давления на температуру плавления. Для этой цели была использована дифференциальная форма уравнения Клапейрона-Клаузиуса. Для натурального каучука его можно выразить как

$$
d T_{m}^{0} / d P=\left(d T_{m}^{0} \Delta v\right) / \Delta H_{u}=0.0465 \mathrm{deg} / \mathrm{atm},
$$

где $\Delta H_{u}=15.3 \mathrm{cal} / \mathrm{g}$ обозначает скрытую теплоту плавления, $T_{m}^{0}=301^{\circ} \mathrm{K}$ - температура плавления при атмосферном давлении, и $\Delta v_{u}=0.098 \mathrm{~cm}^{3} / \mathrm{g}$ - изменение объема на повторяющуюся единицу плавления.

В работах [12] и [13] были исследованы процессы кристаллизации и отжига полиэтилена под высоким давлением, более $2000 \mathrm{~atm}$. Для полиэтилена была найдена скрытая теплота плавления $\Delta H_{u}$ равная $68.0 \mathrm{cal} / \mathrm{g}, T_{m}^{0}=410^{\circ} \mathrm{K}$ и $\Delta v_{u}=0.16 \mathrm{~cm}^{3} / \mathrm{g}$. Тогда $d T_{m}^{0} / d P=0.0235 \mathrm{deg} / \mathrm{atm}$. Таким образом, при давлении $100 \mathrm{MPa}$ температура плавления будет превышать температуру плавления при атмосферном давлении $\Delta T=T_{m}-T_{m}^{0}$ для полиэтилена на $23.5^{\circ}$ и на $46.5^{\circ}$ для натурального каучука. Вундерлих [14], анализируя имеющиеся литературные данные для $T_{m}$ ПЭ при давлениях вплоть до $P=6103 \mathrm{~atm}$, нашел, что зависимость $T_{m}$ от давления может быть описана квадратичным уравнением

$$
T_{m}=415.7+28.1 P-1.66 P^{2},
$$

где давление $P$ выражено в $10^{3} \mathrm{~atm}$, а температура - в градусах Кельвина. При самых низких давлениях наклон этой зависимости составляет $35.2 \mathrm{~K} / 10^{3} \mathrm{~atm}$, т.е. при $P=100 \mathrm{MPa} \mathrm{увеличение} \mathrm{температуры} \mathrm{плавления} \mathrm{РП}$ может составлять около $\Delta T_{m}=35 \mathrm{~K}$. Существует много теорий, описывающих изменение подвижности молекул в полимерах под давлением. Современный анализ всех существующих теорий дан в докторской диссертации Скородумова [15], в которой также показано, что температура плавления $T_{m}$ полимеров в условиях гидростатического давления $100 \mathrm{MPa}$ возрастает на $20-40^{\circ} \mathrm{C}$.

Поэтому мы полагали, что, спекание компактированных таблеток под давлением $100 \mathrm{MPa} \mathrm{при} \mathrm{темпе-}$ ратуре $145^{\circ} \mathrm{C}$, что несколько выше равновесной $T_{m}^{0}$ при атмосферном давлении (по нашим ДСК данным для РП СВМПЭ $\left.5224 T_{m}^{0}=141.5^{\circ} \mathrm{C}\right)$ не приведет к катастрофическому изменению внутренней структуры РП, но обеспечит более эффективную взаимодиффузию молекулярных сегментов на границах частиц. Для подтверждения этой гипотезы и проведения сравнительного анализа кристаллической структуры, формирующейся при спекании компактов при $130^{\circ} \mathrm{C}$ (стандартная процедура) и $145^{\circ} \mathrm{C}$, был изготовлены следующие образцы.

1. Таблетку помещали в предварительно разогретую до $130^{\circ} \mathrm{C}$ пресс-форму, при этой температуре поднимали давление до $100 \mathrm{MPa}$ и выдерживали в пресс-форме $t=30 \mathrm{~min}$. Затем сбрасывали давление, извлекали таблетку и охлаждали до комнатной температуры, поместив таблетку между двумя металлическими пластинами (Standard).

2. Таблетку помещали в разогретую до $130^{\circ} \mathrm{C}$ прессформу и поднимали давление до $100 \mathrm{MPa}$. Затем дополнительно разогревали пресс-форму до $145^{\circ} \mathrm{C}$ и выдерживали при этих условиях $t=30 \mathrm{~min}$. После чего охлаждали пресс-форму до $130^{\circ} \mathrm{C}$ и сбрасывали давление, извлекали таблетку и быстро охлаждали до комнатной температуры (режим I, mode I).

3. Образцы в режиме II (mode II) изготавливались таким же образом, как и образцы в режиме I, но при достижении $130^{\circ} \mathrm{C}$ после сбрасывания давления таблетка охлаждалась до комнатной температуры в пресс-форме.

4. Образцы в режиме III (mode III), в отличие от образцов, полученных в режиме II, охлаждались до комнатной температуры в пресс-форме под давлением $100 \mathrm{MPa}$.

Важно отметить необходимость повышения температуры в пресс-форме до $145^{\circ} \mathrm{C}$ только тогда, когда в ней уже находится таблетка под давлением $100 \mathrm{MPa}$. При сбрасывании давления температура не должна превышать $130^{\circ} \mathrm{C}$. Нахождение таблетки непосредственно в пресс-форме, разогретой до $145^{\circ} \mathrm{C}$ без давления, влечет за собой катастрофические изменения в структуре даже в течение нескольких секунд необходимых для поднятия 
давления, что подтверждается нашими исследованиями спеченных компактов с помощью метода ДСК [16].

\section{3. Большеугловая рентгеновская дифрактометрия (WAXD)}

Дифракционные кривые в широком угловом диапазоне в режиме $\theta-2 \theta$ сканирования от спеченных компактов получали на порошковом рентгеновском дифрактометре D2Phaser, фирмы Bruker, оснащенным медной трубкой и PSD-детектором LynxEye.

На рис. 1 приведена рентгенограмма в диапазоне углов 10-84 градусов по шкале $2 \theta$ от спеченной таблетки реакторного порошка СВМПЭ, полученного по стандартному режиму $\left(T=130^{\circ} \mathrm{C}\right.$ и $\left.P=100 \mathrm{MPa}\right)$. Поскольку дифракционная кривая орторомбического полиэтилена представлена только двумя яркими отражениями от плоскостей (110) и (200), а остальные рефлексы имеют очень слабую интенсивность, на рис. 1 показаны отдельные интервалы в увеличенном масштабе по шкале интенсивности. Интенсивность в интервале для отражения (220) увеличена в 10 раз, а для (330) и $(002)$ - в 50 раз.

\section{4. Методы расчета размеров и искажений кристаллитов}

2.4.1. Метод Шеррера. Известно, что при уменышении размеров областей когерентного рассеяния рентгеновских лучей (кристаллитов) и возникновении в них дефектов различного типа существенно возрастает ширина дифракционных рефлексов по сравнению с инструментальной шириной для идеальных кристаллов больших размеров. Предложено несколько подходов анализа эффектов уширения рефлексов для оценки размеров кристаллитов и их дефектности. Простейший из них метод Шеррера [17], предполагающий, что уширение обусловлено исключительно малыми размерами кристаллитов, внутренняя структура которых бездефектна.

В этом приближении оценка усредненных размеров кристаллитов $D_{\mathrm{hkl}}$ в направлении, перпендикулярном плоскостям (hkl), проводится по формуле:

$$
D_{\mathrm{hkl}}=k \lambda /(\Delta 2 \theta)_{t} \cos \theta_{m},
$$

где: $\theta_{m}-$ угловое положение пика (максимума) рефлекса, rad.; $(\Delta 2 \theta)_{t}$ - истинная линейная полуширина рефлекса, рад.; $\lambda$ - длина волны используемого излучения; $\kappa-$ постоянная Шеррера, которую чаще всего принимают равной $\kappa=0.9$. (Более детально - см. [18]).

Априори можно утверждать, что данный „идеализированный“ подход позволяет получить лишь приблизительную оценку размеров кристаллитов, которые не могут использоваться для установления корректных соотношений структура-свойства. К сожалению, вследствие своей простоты этот метод слишком часто используется до сих пор.

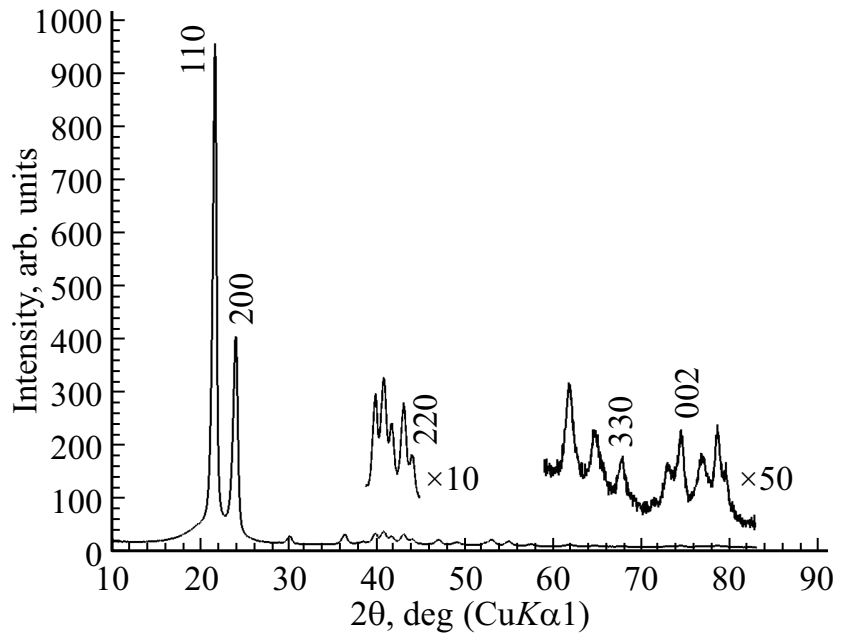

Рис. 1. Рентгеновская большеугловая дифракционная кривая исходной спеченной таблетки порошка СВМПЭ-5224.

2.4.2. Метод Вильямсона-Холла. Метод несколько расширяет возможности метода Шеррера, поскольку учитывает дополнительный вклад в уширение рефлексов дефектов I рода, обусловленных наличием в объеме поликристаллического материала неоднородных внутренних механических напряжений. Чтобы разделить эффекты дисперсности размеров кристаллитов и микроискажений, необходимо провести измерения не менее трех порядков отражения от одной системы плоскостей и воспользоваться различной зависимостью дисперсности и микроискажений от $\sin \theta / \lambda$. Например, если считать, что уширение за счет дисперсности и за счет микроискажений описывается функцией Коши, то можно построить зависимость для разных порядков отражения в виде

$$
\beta=k \lambda / D \cos \theta+\varepsilon 4 \tan \theta,
$$

где $\beta$ - физическое уширение дифракционного максимума; $\lambda$ - длина волны $\mathrm{Cu} K_{\alpha}$-излучения; $K-$ константа Шеррера (можно принять равной единице); $D$ - размер областей когерентного рассеяния; $\theta-$ Брегговский угол; $\varepsilon$ - величина микроискажений кристаллической решетки.

Видоизменим функцию (4) как

$$
\beta \cos \theta=\lambda / D+\varepsilon 4 \tan \theta
$$

видим, что это есть уравнение прямой, где отрезок, отсекаемый по оси ординат, даст величину $\lambda / D$. Из полученной линейной функции $\beta \cos \theta / \lambda$ от $4 \sin \theta / \lambda$ можно рассчитать значения среднего размера ОКР и $\varepsilon$.

Если обе функции имеют вид $e^{-\alpha x^{2}}$ (функции Гаусса), то построим аналогичную зависимость для двух-трех порядков отражения в виде

$$
((\beta \cos \theta) / \lambda)^{2}=\left(K / D_{110}\right)^{2}+((\varepsilon 4 \sin \theta) / \lambda)^{2},
$$

где $\varepsilon-$ величина микронапряжений кристаллической решетки. 
2.4.3. Метод Хоземанна. Анализ дифракционных картин от частично-кристаллических полимеров показывает, что по сравнению, например, с металлами, их рентгенограммы содержат существенно меньше рефлексов, и при этом наблюдается значительное уменьшение интенсивности и увеличение полуширины рефлексов для дальних порядков. Эти необычные эффекты Хоземанн [19] объяснил на основе новой концепции паракристаллического характера агрегации структурных элементов в малоупорядоченных системах и возникновении искажений II рода. В исследованных нами образцах такими структурными элементами являются пластинчатые ламели мозаичного строения, состоящие из кристаллитов из складчатых молекул. В подобных системах нет строгой периодичности дальнего порядка в расположении мотивов, и появляются флуктуации расстояний между мотивами, которые возрастают с увеличением расстояния от выбранного начала координат и, кроме того, сказываются на всех остальных расстояниях. Поэтому функция распределений местоположения соседей вместо идеально периодической при наличии дефектов I рода становится статистической паракристаллической функцией распределения второго рода, в которой сравнительно отчетливо выражено распределение первых соседей, т.е. ближний порядок. Чем далее расположен мотив, тем более размытой становится функция распределения, и при некотором расстоянии (радиус взаимодействия, область упорядоченности, размер паракристалла) нарушаются условия когерентного рассеяния рентгеновских лучей на слабо упорядоченной системе.

В методе Хоземанна [19] размеры паракристаллов $\mathrm{D}_{\mathrm{hkl}}$ и величины паракристаллических искажений $g$ рассчитываются на основании интегральных интенсивностей рефлексов нескольких порядков.

Интегральная полуширина рефлекса $\Delta \beta(b)$ определялась как

$$
\Delta \beta)(b)=\frac{\int_{b_{1}}^{\beta_{2}} I(b) d b}{I_{\max }},
$$

где: $I(b)$ - интенсивность рассеяния после вычитания фона и аппаратурных искажений, $I_{\max }-$ интенсивность рефлекса в максимуме.

Первоначальную зависимость интенсивности рефлекса от угла рассеяния Брегга $2 \theta$ перестраивали в зависимость от угла рассеяния $b=2 \sin \theta / \lambda$, где $\lambda-$ длина волны рентгеновского излучения, в соответствии с формулой

$$
\Delta b=((2 \cos \theta) / \lambda) \Delta \theta .
$$

В работе для всех исследованных образцов определялись размеры паракристаллов и паракристаллических искажений на основании анализа интегральных интенсивностей трех порядков отражений от плоскостей (110), (220) и (330) для орторомбических кристаллических элементарных ячеек.
Интегральная полуширина рефлексов любого порядка отражения от кристаллических плоскостей (hkl) связана с размером $D_{110}$ кристаллитов, перпендикулярных к этим плоскостям, и величиной паракристаллических искажений $g_{110}$ следующим выражением [19]:

$$
\Delta \beta=1 / D_{110}+\left(\pi g_{110}\right)^{2} d_{110} b^{2},
$$

где $d_{110}$ - период идентичности (или усредненный период) в перпендикулярном направлении к плоскостям (110), (220) и (330).

Если построить график в координатах $\Delta \beta-b^{2}$, то для трех порядков отражения должна наблюдаться прямая линия, отсекающая на Ү-оси отрезок, равный $\Delta \beta_{0}=1 / D_{110}$. Из наклона прямой $\operatorname{tg} \alpha$ находится величина паракристаллических искажений $g_{110}$

$$
g_{110}=\sqrt{\frac{\operatorname{tg} \alpha}{\pi^{2} d_{110}}} .
$$

\section{3. Результаты и обсуждение}

В качестве примера на рис. 2-4 приведены три выделенных фрагмента экспериментальных дифрактограмм от спеченного реакторного порошка 5224, полученного по режиму I (mode I). На данных фрагментах отчетливо видны несколько перекрывающихся дифракционных максимумов, соответственно:

Рис. 2 - область углов дифракции $2 \theta$ от 14 до 38 градусов (первые порядки отражения от плоскостей (110) и (200) орторомбической ячейки).

Рис. 3 - область углов дифракции $2 \theta$ от 38 до 45 градусов (дифракционные пики второго порядка отражения от плоскостей (220) ячейки, а также рефлексы от плоскостей (011), (310), (111) и (201)).

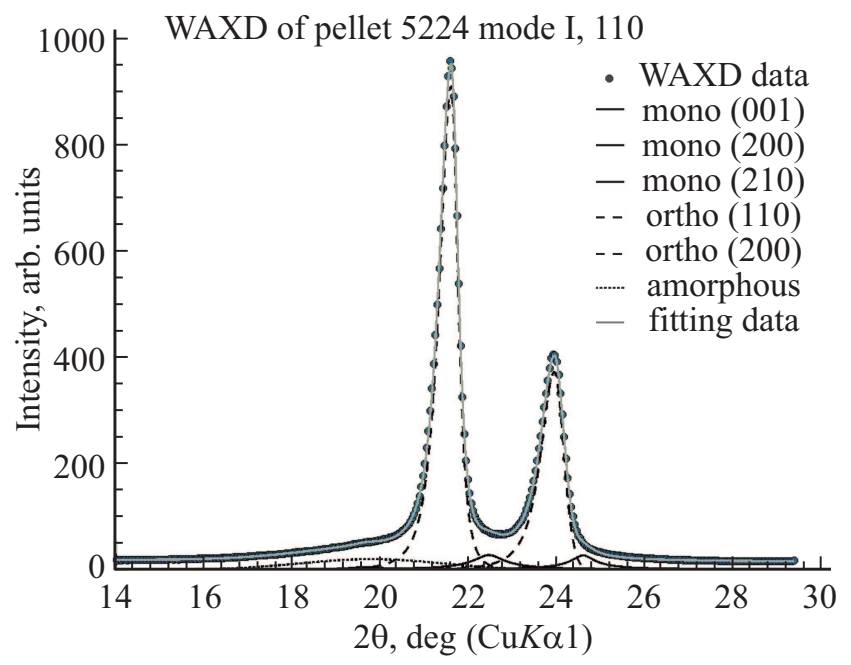

Рис. 2. Разложение перекрывающихся рефлексов на составляющие для экспериментальной дифрактограммы первого порядка отражения (110) в диапазоне углов 14-28 градусов по $2 \theta$. $\left(R^{2}=0.99942\right.$, и $\left.\chi^{2}=0.03367\right)$. 


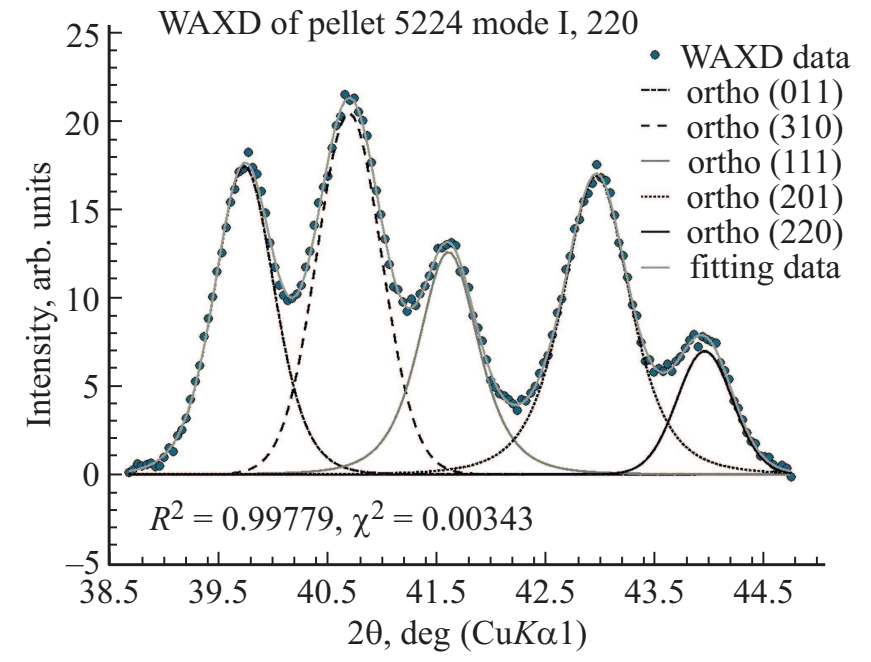

Рис. 3. Разложение перекрывающихся рефлексов на составляющие для экспериментальной дифрактограммы второго порядка отражения (220) в области углов 38-45 градусов по $2 \theta$.

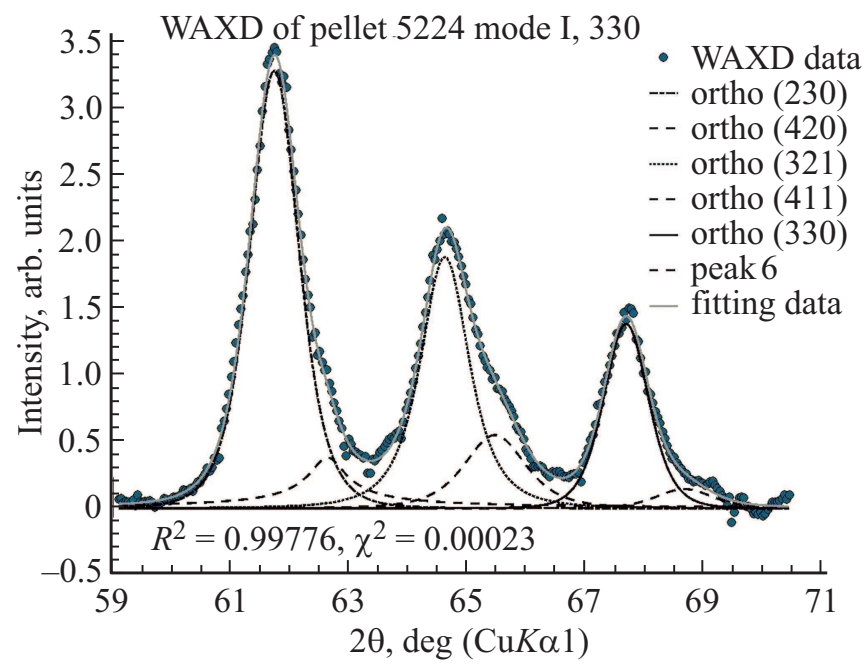

Рис. 4. Разложение перекрывающихся пиков на составляющие для экспериментальной дифрактограммы третьего порядка отражения (330) в области углов $2 \theta \quad 59-69.8^{\circ}$.

Рис. 4 - область углов дифракции $2 \theta$ от 59 до 70 градусов (дифракционный пик третьего порядка отражения от плоскостей (330), а также рефлексы от плоскостей (230), (420), (321) и (411)).

Поскольку в методе Хоземанна для дальнейшего анализа необходимо получение наиболее корректных значений интегральных интенсивностей трех порядков отражения от плоскостей (110), (220) и (330), потребовалось провести компьютерное разложение сложных дифрактограмм, представленных на рис. 2, 3 и 4.

Экспериментальные данные были разложены на отдельные пики подгонкой профильных функций с помощью программы LIPRAS MATLAB [20]. Использовали профильные симметричные функции Гаусса, Пирсон-VII и псевдо-Фойгта. Подгонку осуществляли, используя алгоритмы Trust-Region-ReflectiveLeastSquares и Левенберга-Марквардта [21]. Качество подгонки и разложения оценивали коэффициентом детерминации $R^{2}$ и критерием согласия $\chi^{2}$ (см. рис. 2 ).

Фрагмент экспериментальной дифрактограммы первого порядка отражения на фоне двух больших перекрывающихся пиков орторомбической фазы $2 \theta_{(110)}=$ $=21.47$ град. и $2 \theta_{(200)}=23.78$ град. содержит ряд малоинтенсивных перекрывающихся пиков моноклинной фазы: $m_{001}(2 \theta=19.67$ град. $), m_{200}(2 \theta=22.45$ град. $)$ и $m_{-201}(2 \theta=24.59$ град.).

На рис. 3. показано разложение перекрывающихся рефлексов с помощью подгоночной профильной функции Пирсон-VII. Параметр $m$ был близок 10. Дифракционная кривая в области углов $38-45$ градусов по $2 \theta$ содержит пять пиков относящихся к орторомбической фазе: (011), (310), (111), (201), (220).

Разложение перекрывающихся рефлексов в области углов 59-69.8 градусов по $2 \theta$, показанное на рис. 4, содержит пики, относящиеся только к орторомбической фазе: (230), (420), (321), (411), (330).

Как было показано ранее в литературе (см., например, [22]), для полимерных кристаллов более корректной является обработка рентгенодифракционных данных по методу Хоземанна, описанному выше в разделе „Экспериментальная часть“. Если построить график в координатах $\Delta \beta-b^{2}$, то для трех порядков должна наблюдаться прямая линия, отсекающая на Ү-оси отрезок, равный $\Delta \beta_{0}=1 / D_{110}$. Из наклона прямой $\operatorname{tg} \alpha$ находится величина паракристаллических искажений $g_{110}$.

Действительно, в нашем случае для всех исследованных образцов наблюдалась прямолинейная зависимость $\Delta \beta$ от квадрата вектора рассеяния, что свидетельствует о том, что уширение наблюдаемых рефлексов в основном обусловлено паракристаллической природой ОКР.

Пример такого графика показан на рис. 5.

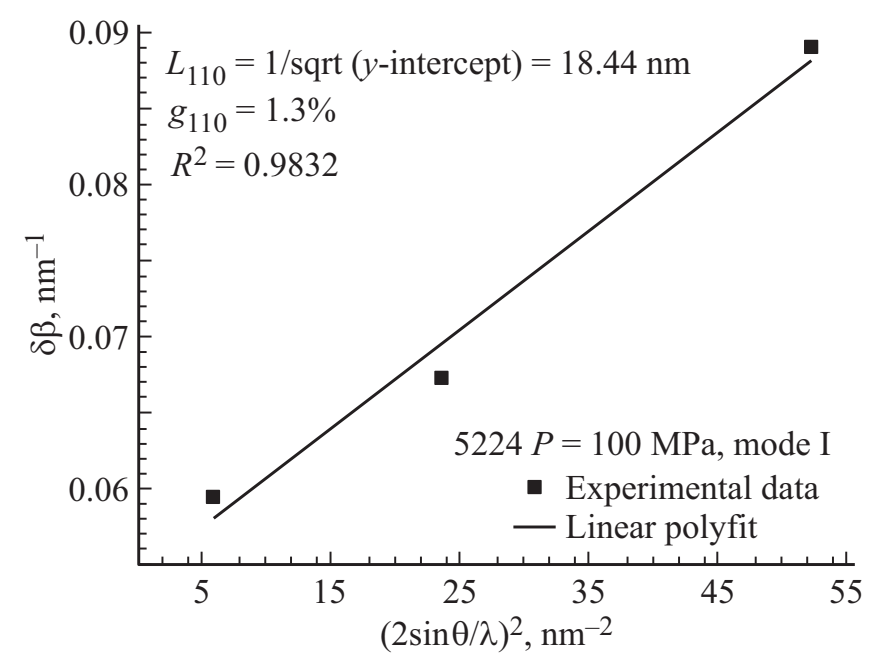

Рис. 5. Зависимость $\Delta \beta(b)$ от $b^{2}$ (формула (9)) для таблетки 5224 , спеченной при давлении $100 \mathrm{MPa}$ и температуре $145^{\circ} \mathrm{C}$ и быстро охлажденной (mode I). 
Таблица 1. Сводная таблица размеров кристаллитов и искажений решетки в образцах СВМПЭ серии 5224, приготовленных при различных режимах спекания

\begin{tabular}{l|c|c|c|c|c|c|c}
\hline \multirow{2}{*}{ Sample } & \multicolumn{3}{|c|}{ Method Hosemann } & \multicolumn{3}{c}{ Williamson-Hall approach } \\
\cline { 2 - 7 } & $D_{110}, \mathrm{~nm}$ & $D_{002}, \mathrm{~nm}$ & $g_{110}, \%$ & $R^{2}$ & $D_{110}, \mathrm{~nm}$ & $\varepsilon$ & $R^{2}$ \\
\hline Mode I & 18.44 & 11.40 & 1.3 & 0.9832 & 17.16 & 0.00491 & 0.9711 \\
Mode II & 16.17 & 10.03 & 0.85 & 0.9956 & 14.48 & 0.00323 & 0.9920 \\
Mode III & 18.18 & 10.01 & 1.4 & 0.9624 & 17.24 & 0.00547 & 0.9477 \\
Standard & 17.76 & 9.76 & 1.6 & 0.8955 & 17.83 & 0.00667 & 0.8896
\end{tabular}

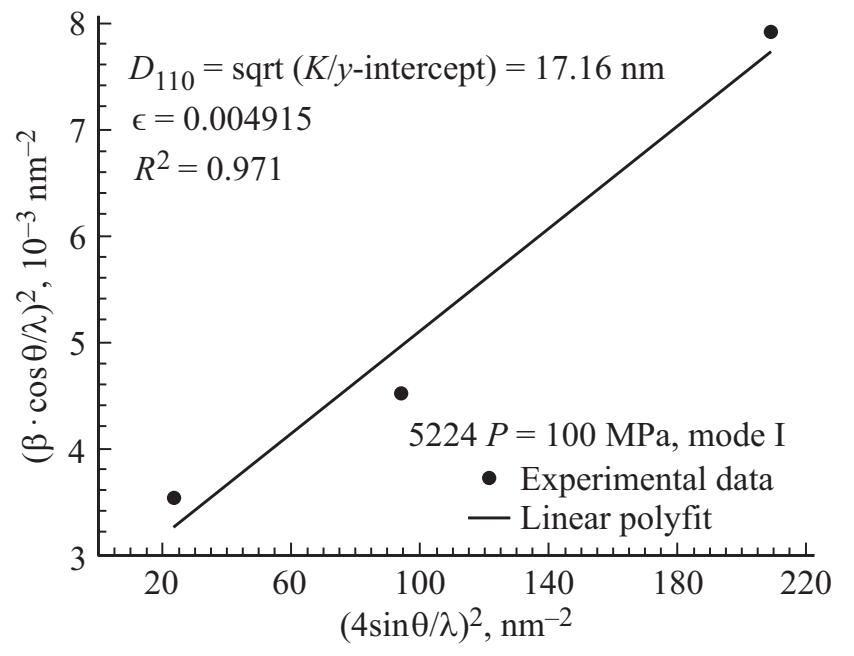

Рис. 6. Аппроксимация Вильямсона-Холла (формула 6)) для таблетки 5224, спеченной при давлении $100 \mathrm{MPa} \mathrm{и} \mathrm{температу-}$ pe $145^{\circ} \mathrm{C}$ и быстро охлажденной (mode I).

Подгонка экспериментальных рефлексов проводилась с помощью профильной функции Pearson VII, в которой значения индекса $m$ были близки к 10. При этих значениях функция Pearson VII описывается как функция Гаусса. При $m \sim 1$ функция Pearson VII близка к функции Лоренца.

Из анализа опубликованных ранее данных, выполненных на образцах полимеров, следует, что в большинстве случаев дефекты кристаллов имеют паракристаллическую природу и в редких случаях обусловлены внутренними механическими напряжениями [23]. Чтобы рассмотреть возможность существования микронапряжений в спеченных таблетках, мы рассчитали поперечные размеры кристаллитов и величины микронапряжений, используя метод Вильямсона-Холла, описанный выше. Для профильной функции Пирсон VII использовали коррекцию интегрального уширения для гауссового профиля и построили по формуле (8) график, показанный на рис. 6 (от Коши уравнения (5), он отличается как график с координатами в „квадрате“)

Приведем сводную табл. 1 размеров кристаллитов $D_{110}$ в $\mathrm{nm}$, величины паракристаллических искажений $g_{110}($ в \%) и величины $\varepsilon$ микронапряжений решетки для кристаллитов, перпендикулярных к плоскостям (110), (220) и (330) для стандартного образца и трех режимов спекания таблеток порошка 5224, рассчитанные двумя методами: Хоземанна и Вильямсона-Холла. Размер кристаллита $D_{002}$ в направлении, перпендикулярном плоскости (002) был определен в предположении, что величина паракристаллических искажений $g=0$.

Для большей наглядности размеры кристаллитов $D_{110}$, рассчитанные по модели паракристалла (Hosenann) и в предположении о преимущественном влиянии микронапряжений на уширение рефлексов $(\mathrm{W}-\mathrm{H})$, представлены на рис. 7 графически.

Размеры кристаллитов $D_{110}$, вычисленные по методу Вильямсона-Холла, оказались на 7.5\%-11.7\% меньше в зависимости от режимов охлаждения при близких значениях в исходных образцах с методом Хоземанна.

Важно отметить, что спекание при температуре выше $T_{m}^{0}$ полиэтилена в условиях режимов I и III приводит к незначительному увеличению поперечного размера кристаллитов $D_{110}$ на $3.8-2.7 \%$ (в зависимости от условий охлаждения) по сравнению со стандартным образцом, спеченным при $T<T_{m}^{0}$. Однако в таблетках, изготовленных по режиму II (медленное охлаждение в

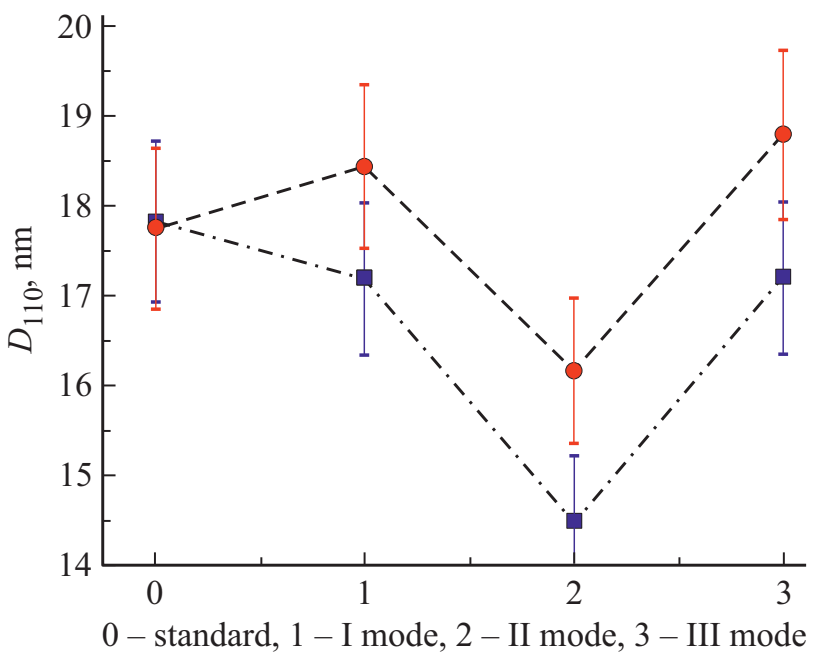

Рис. 7. Размеры кристаллитов $D_{110}$ в спеченных таблетках РП СВМПЭ 5224, изготовленных в разных условиях. Расчет по паракристаллической модели (штриховая линия), расчет по $W_{H}$ (штрихпунктирная линия). 

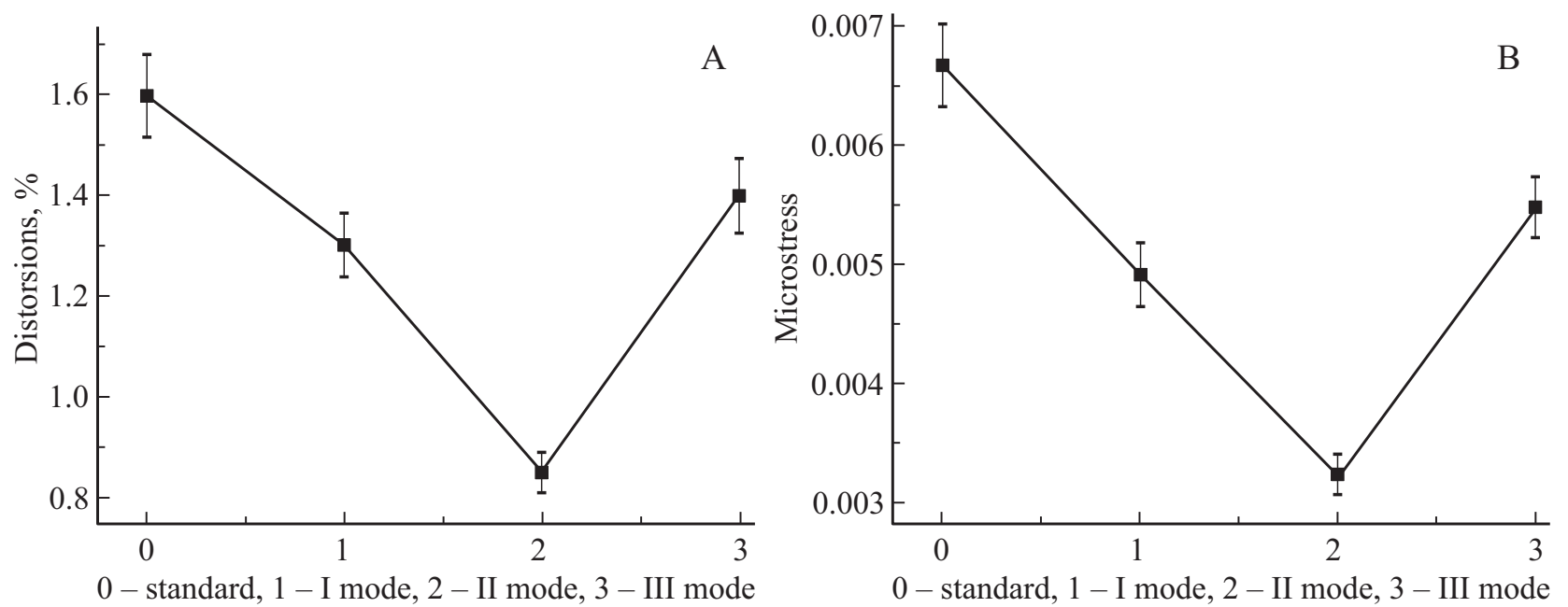

Рис. 8. Паракристаллические искажения (А) и микронапряжения (В) исследованных образцах.

пресс-форме без давления) величина $D_{110}$ оказывается заметно меньше, чем в стандартном образце (на 9.8\%).

Однозначно сказать о причине наблюдаемого эффекта в настоящее время не представляется возможным. Однако, анализ данных, полученных при переработке порошкообразных полимеров и опубликованных в [24], позволил нам предположить, что при медленном охлаждении таблетки РП СВМПЭ (режим II) без давления до комнатной температуры в неупорядоченных областях на границах между частицами порошка происходит вторичная кристаллизация. Размеры этих вновь образованных кристаллитов, по-видимому, меньше чем размеры кристаллитов основной массы в силу ограниченного пространства и недостатка материала. Наряду с этим происходит усовершенствование первичных кристаллитов и уменьшение искажений в них. Появление мелких кристаллитов и усовершенствование ранее образовавшихся ОКР обусловливает меньшие размеры ОКР в образцах, полученных по режиму II.

Из табл. 1 следует также, что спекани е при $145^{\circ} \mathrm{C}$ сопровождается снижением дефектности кристаллической решетки. Величины паракристаллических искажений $g_{110}$, рассчитанные в паракристаллической модели Хоземанна для всех трех образцов, спеченных в разных модах при $145^{\circ} \mathrm{C}$, меньше, чем паракристаллические искажения в стандартном образце, спеченном при $130^{\circ} \mathrm{C}$,

Таблица 2. Параметры орторомбической кристаллической ячейки порошков СВМПЭ 5224, спеченных под давлением $100 \mathrm{MPa} \mathrm{в} \mathrm{разных} \mathrm{условиях}$

\begin{tabular}{l|c|c|c}
\hline Sintering & $a,( \pm 0.004) \mathrm{nm}$ & $b,( \pm 0.004) \mathrm{nm}$ & $c,( \pm 0.004) \mathrm{nm}$ \\
\hline Mode I & 0.748 & 0.496 & 0.255 \\
Mode II & 0.748 & 0.497 & 0.255 \\
Mode III & 0.750 & 0.497 & 0.255 \\
Standard & 0.750 & 0.498 & 0.255
\end{tabular}

что особенно заметно в образце II (рис. 8, слева). Микронапряжения повторяют тот же ход зависимости от образца к образцу.

Размеры элементарной ячейки $a, b$ и $c$ орторомбических кристаллов, рассчитанные из большеугловой экспериментальной рентгенодифрактограммы приведены в табл. 2.

Размеры элементарной ячейки $a, b$ и $c$ для всех трех режимов спекания в пределах экспериментальной ошибки измерения остаются постоянными.

\section{4. Заключение}

Проведен сравнительный рентгеноструктурный анализ порошков СВМПЭ, спеченных при температурах ниже и выше равновесной температуры плавления полиэтилена при атмосферном давлении $\left(T_{m}^{0}\right)$. Рассчитаны размеры кристаллитов в направлениях , перпендикулярных кристаллографическим плоскостям (110) и (002). Найдено, что заметное уменьшение поперечных размеров кристаллитов $\left(D_{110}\right)$ по сравнению с их размерами в стандартных образцах, спеченных при $T<T_{m}^{0}$, наблюдается только в образцах, остывающих после спекания в прессе без давления (режим II). Вычисления производились при использовании модели паракристалла Хоземана и по методу Вильямсона-Холла. Размеры кристаллитов $D_{110}$, вычисленных в предположении о паракристаллическом строении областей порядка, для всех исследованных образцов были на $20 \%$ выше, чем рассчитанные в предположении о расширении рефлексов за счет микронапряжений. Это не изменяет выше сделанный вывод, но требует дальнейшего анализа с учетом наличия рефлексов метастабильной моноклинной фазы, существующей только под напряжением. Продольные размеры кристаллитов $\left(D_{002}\right)$ также практически не зависят от температуры спекания. Исключение составляет только быстро охлажденный после спекания порошок 
(режим I), в котором величина $D_{002}$ оказалась на $14 \%$ больше, чем у остальных образцов.

Сделан вывод, что спекание реакторных порошков СВМПЭ под давлением $100 \mathrm{MPa} \mathrm{при} T>T_{m}^{0}$ не приводит к существенным изменениям в кристаллической структуре полимера и они могут использоваться как прекурсоры для ориентационного упрочнения материала. Дальнейшее исследование деформационно-прочностных свойств прекурсоров покажет, насколько повышение температуры спекания компактов оказалось эффективным для увеличения прочности межчастичных границ.

\section{Финансирование работы}

Работа выполнена при финансовой поддержке Российского фонда фундаментальных исследований (коды проектов 19-03-00789, 19-29-12049 и 18-29-17023 mk).

\section{Конфликт интересов}

Авторы заявляют, что у них нет конфликта интересов.

\section{Список литературы}

[1] М.Б. Константинопольская, С.Н. Чвалун, В.И. Селихова, А.Н. Озерин, Ю.А. Зубов, Н.Ф. Бакеев. Высокомолекулярн. соединенения 27 А, 538 (1985).

[2] В.И. Селихова, Ю.А. Зубов, Е.А. Синевич, С.Н. Чвалун, Н.И. Иванчева, О.В. Смольянова, С.С. Иванчев, Н.Ф. Бакеев. Высокомолекулярн. соединенения 34А, 92 (1992).

[3] Е.А. Синевич, В.А. Аулов, Н.Ф. Бакеев. Высокомолекулярн. соединения 50A, 1515 (2008).

[4] S. Rastogi, Y. Yao, S. Ronca, J. Bos, J. Van der Eem. Macromolecules 44, 5568 (2011).

[5] В.Н. Варюхин, В.Ф. Дроботько, С.С. Иванчев, В.А. Марихин, Л.П. Мясникова, Н.Е. Письменова, Е.И. Радованова, C.А. Терехов, М.А. Яговкина. Сб. материалов. XXIII Петербургские чтения по проблемам прочности. Изд-во BBM ( 2018). C. 352. ISBN 978-5-9651-1135-0.

[6] С.С. Иванчев, А.Н. Озерин, Н.И. Иванчева, С.Н. Чвалун, И.И. Олейник, Н.Ф. Бакеев, М.Г. Еремеева, Е.В. Свиридова, В.А. Аулов, И.В. Олейник, А.С. Кечекьян. Патент PФ RU (11) 2552636 (13) C2.

[7] G.W. Halldin, I.L. Kamel. Polymer Eng. Sci. 17, 26 (1977).

[8] В.А. Аулов, С.В. Макаров, И.О. Кучкина, А.Н. Озерин, Н.Ф. Бакеев. Высокомолекулярн. соединенения А42, 1850 (2000).

[9] L.P. Myansikova, Yu.M. Boiko, V.M. Egorov, E.M. Ivan'kova, D.V. Lebedev, V.A. Marikhin, E.I. Radovanova, G.H. Michler, V. Seidewitz, S. Goerlitz. Ch. 5 in Reactor Powder Morphology/Ed. P. Lemstra, L. Myasnikova. Nova Sci. Publ., USA (2011).

[10] D.E. Roberts, L. Mandelkern. J. Am. Chem. Soc. 77, 786 (1955).

[11] G.M. Martin, L. Mandelkern. J. Appl. Phys. 34, 2317 (1963).

[12] J. Osugi, K. Hara, N. Hirai, J. Hikasa. Rev. Phys. Chem. Jpn 34, 64 (1965).

[13] R. Wunderlich, T. Arakawa. J. Polym. Sci. A, 2, 3706 (1964).

[14] B. Wunderlich. Macromolecular physics. Crystal nucleation, growth, annealing. Academic Press, N.Y. (1976). V. 2. 560 p.
[15] В.Ф. Скородумов. Дис. д.ф.м.н. М. (2010). 419 с.

[16] Л.П. Мясникова, В.Ф. Дроботько, А.П. Борзенко, Н.Е. Письменова, Е.М. Радованова, Ю.М. Бойко, В.А. Марихин, А.К. Борисов, В.М. Егоров. В сб.: Актуальные проблемы прочности. Витебск (2020).

[17] J.I. Langford, D. Loufir. Rep. Prog. Phys. 59, 131 (1996).

[18] Modern Powder Diffraction/Ed. D. Bish, Post J. Chelsea. Michigan: Mineralogical Society of America 20 (1989).

[19] R. Hosemann, W. Wilke. Makromol. Chem. 118, 249 (1968).

[20] G. Esteves, K. Ramos, C.M. Fancher, J.L. Jones. LIPRAS: Line-profile Analysis Software (2017); DOI: $10.13140 /$ RG.2.2.29970.25282/3.

[21] https://www.mathworks.com/help/optim/ug/least-squaresmodel-fitting-algorithms.html.

[22] Ю.М. Бойко, К. Stahl, В.А. Марихин, Л.П. Мясникова. Высокомолекулярн.соединения 9А, 1992 (2007).

[23] Ю.А. Зубов, В.И. Селихова, В.А. Каргин. Высокомолекулярн. соединения. 9А, 364 (1967).

[24] Л.А. Игонин Высокомолекулярн. соединения 10А, 2726 (1968).

Редактор Т.Н. Василевская 